\title{
Morphofunctional characteristics of single combats athletes as factors of success
}

Olha O. Podrihalo ${ }^{1 \mathrm{ABCDE}}$, Leonid V. Podrigalo ${ }^{1,2 \mathrm{ABCDE}}$, Wladyslaw Jagiello ${ }^{3 \mathrm{BCDE}}$, Olexandr V. Podavalenko ${ }^{1 \mathrm{ADE}}$, Irina P. Masliak ${ }^{1 \mathrm{DE}}$, Yuri M. Tropin ${ }^{1 \mathrm{BDE}}$, Margarita A. Mameshina ${ }^{1 \mathrm{DE}}$, Volodymyr O. Galimskyi ${ }^{4 \mathrm{BDE}}$, Inna I. Galimska ${ }^{4 \mathrm{BDE}}$

${ }^{1}$ Kharkiv State Academy of Physical Culture, Kharkiv, Ukraine

${ }^{2}$ V. N. Karazin Kharkov National University, Kharkiv, Ukraine

${ }^{3}$ Gdansk University of Physical Education and Sport, Gdańsk, Poland

${ }^{4}$ Flight Academy National Aviation University, Kropivnitsky, Ukraine

Authors' Contribution: A - Study design; B - Data collection; C - Statistical analysis; D - Manuscript Preparation; E - Funds Collection.

\begin{abstract}
Background and Study Aim Material and Methods The aim of the article is a comparative analysis
various types of martial arts as factors of success.

The study participated students involved in martial arts $(n=29$; age $-17.53 \pm 0.15$ years). The first group (group 1 - wrestlers) included judo, sambo, wrestling athletes $(n=12$, age $-18.58 \pm 0.38$ years). The second group (group 2 - athletes of percussion martial arts) included athletes of karate, taekwondo (GTF), taekwondo (WTF), ( $\mathrm{n}=17$; age - $18.12 \pm 0.26$ years). Determined 46 morphofunctional indicators: length and body weight; chest circumference in a pause, on inhalation and exhalation; length and circumference of the segments of the upper and lower extremities; wrist dynamometry. A goniometric study of the range of motion in the joints of the upper extremities was carried out. The dynamic grip strength was determined by the maximum frequency of hand squeezing in 10 seconds. To characterize the data, the median was determined - the first (25\%) and third (75\%) quartiles. Differences between groups were assessed using nonparametric criteria of Wilkinson-Mann-Whitney (U) and Rosenbaum (Q).

Results Athletes in group 1 had a greater interquartile range compared to athletes in group 1 in the following indicators: body weight; chest circumference in a pause, on inhalation and exhalation; hand dynamometry of the right and left hands; maximum frequency of the hand grip in the impulse mode with the left hand; shoulder width; circumference of the shoulder, forearm, thigh and lower leg. Athletes of percussion martial arts were characterized by large values of the shin length. The amplitude of abduction and adduction in the right wrist joint, the amplitude of abduction in the left wrist joint was greater in the wrestlers. Athletes of percussion martial arts had a large amount of extension of the left wrist joint, flexion of the right elbow joint, extension and abduction of the right shoulder joint.

Conclusions Analysis of morphofunctional indicators of athletes of various types of martial arts confirmed the specific effect of the sport on the body of athletes. The features that are the factors of success are highlighted. For wrestlers, these include hand strength in various modes. It allows to implement quickly and efficiently grip. This is the basis for a successful wrestling technique. Sufficient development of the muscles of the limbs ensures the execution of throws in wrestling. The lengthened calf size contributes to a more effective kick in martial arts. Goniometric features of movements reflect the possibility of high-quality gripping, striking or blocking. The used morphofunctional indicators can be applied to predict the success of athletes in various types of martial arts.

Keywords: martial arts, anthropometric indicators, goniometric criteria, physical development, success.
\end{abstract}

\section{Introduction}

The effectiveness of sports activity is predicted on the basis of a comprehensive assessment of the athlete's characteristics. An important place among them is taken by the state of health, somatotype, level of physical qualities. Analysis of anthropometric status and physique is considered the basis for achieving success in a particular sport [1]

Body shape and morphology are the leading factors in sports performance. The study of anthropometric

\footnotetext{
(c) Olha O. Podrihalo, Leonid V. Podrigalo, Wladyslaw Jagiello, Olexandr V. Podavalenko, Irina P. Masliak, Yuri M. Tropin, Margarita A. Mameshina, Volodymyr O. Galimskyi, Inna I. Galimska, 2021 doi:10.15561/20755279.2021.0502
}

indicators and somatotype is used to assess and analyse the state of a certain population and possible trends in growth and development over a certain period of time [2]. These indicators are used in sports science to study various aspects of the impact of exercise on athletic performance. This line of research allows us to identify promising athletes in many sports [3]. Other studies have confirmed the importance of anthropometric indicators and body proportions for the growth of skill in various sports [4, 5]. Dopsaj et al. [6] studied the body composition of elite martial arts athletes. It was concluded that the body composition of athletes is one of the main predictors of success. The authors have developed a model of body structure, reflecting the specifics of the type of martial arts.

The analysis of biometric data of single combats 
athletes allows to highlight the peculiarities of the somatotype [7]. These data are the basis for prediction. The authors note that the specific anthropometric profile of an athlete is the basis for predicting success in sports. Features of physical development and constitution of freestyle wrestlers were evaluated in other studies [8]. The authors have established the characteristic features of the somatotype. It is noted that the brachymorphic body type prevails in wrestlers. This is assessed as a success factor.

The somatotype is one of the elements that distinguish athletes from people who do not go in for sports systematically [9]. The importance of studying the somatotype of martial arts athletes using various methods is emphasized. This allows you to make a forecast and assess the effectiveness of training athletes. The effectiveness of the forecast depends on the tests and indicators used. These tests should reflect the specifics of the sport [10].

The increase in success in martial arts depends on the optimal body composition, the development of muscle strength, flexibility, anaerobic and aerobic potential [11]. The authors propose strategies for training athletes based on monitoring body weight.

Features of physical development determine the style of conducting a duel in single combats [12]. The authors have established the relationship between the style of fighting, the functional asymmetry of the brain in elite Greco-Roman wrestling athletes. They are rated as an important predictor of success. Casals et al. [13] determined anthropometric indicators that predict the effectiveness of special tests in judo. Regression models were built based on the results obtained. An increase in muscle and bone mass, and less severity of ectomorphia were associated with better performance of athletes in a special fitness test.

The aim of the study was a comparative analysis of the morphofunctional characteristics of athletes of various types of martial arts as factors of success.

\section{Materials and methods}

\section{Participants}

The study participated students involved in martial arts $(\mathrm{n}=29$; age $-17.53 \pm 0.15$ years $)$. The level of sportsmanship ranged from athletes with little training experience to experienced athletes with long training experience. There were no differences between the groups in terms of skill level. The participants were divided into 2 groups depending on the type of martial arts. Group 1 includes athletes $(n=12)$ wrestling (judo, sambo, GrecoRoman and freestyle wrestling). The average age of the athletes in this group was $(18.58 \pm 0.38)$ years. Group 2 includes athletes $(\mathrm{n}=17)$ percussion martial arts [karate, taekwondo (GTF), taekwondo (WTF)]. The average age of the athletes in this group was $(18.12 \pm 0.26)$ years. Differences in age between the groups are insignificant $(\mathrm{p}>0.05)$.

Research Design

The study design involved the determination of 46 morphofunctional indicators. The measurements were carried out in accordance with the requirements of the international unified method of anthropometric research [14]. The study determined: body length and weight; chest circumference in a pause, on inhalation and exhalation; the length and circumference of the segments of the upper and lower extremities; wrist dynamometry.

A goniometric study of the range of motion in the joints of the upper extremities was carried out. An IGaging ${ }^{\circledR}$ electronic goniometer (China) was used. The study determined the following: adduction, abduction, flexion and extension in the wrist joints; flexion and extension in the elbow joints; adduction, abduction, flexion and extension in the shoulder joints.

The maximum grip frequency (MX) in the pulsed mode was determined using an electronic device "Kepai" (China). The research methodology assumed considering the maximum number of device compressions in 10 seconds. One compression was equivalent to $10 \mathrm{~kg}$.

This study was approved by the Bioethics Committee for Clinical Research and conducted according to the Declaration of Helsinki. All participants gave their written consent to research (protocol of the Commission on Bioethics of the Kharkov State Academy of Physical Culture No. 35/09-10) and were informed about the purpose and test procedures and about the possibility of withdrawal of consent at any time for any reason.

\section{Statistical Analysis}

Statistical analysis of the data obtained was carried out using licensed Excel spreadsheet packages. To characterize the data, the median was determined: the first $(25 \%)$ and third $(75 \%)$ quartiles. Differences between groups were assessed using nonparametric criteria of Wilkinson-Mann-Whitney (U) and Rosenbaum (Q).

\section{Results}

The results obtained are shown in tables 1,2 .

The presented results confirm the differences in morphological parameters. The wrestlers had a greater interquartile range in comparison with athletes of percussion single combats in a number of indicators. These include: body weight; chest circumference in a pause, on inhalation and exhalation; hand dynamometry of the right and left hands; maximum grip frequency in pulse mode with the left hand; shoulder width. Differences in the values of the wrist dynamometry were also confirmed using Rosenbaum index. For the right hand, $Q=7$, for the left $-\mathrm{Q}=9, \mathrm{p}<0.05$.

The perimeters of the limb segments (circumference of the shoulder, forearm, thigh and lower leg) were also characterized by a large interquartile range in wrestlers. Differences in the circumference of the right shoulder, right forearm and left shoulder were confirmed using Wilkinson-Mann-Whitney index (respectively, $\mathrm{U}=47$, $U=49, U=44, p<0.05$ ). The group of athletes of percussion martial arts was characterized by large values of the longitudinal dimensions of the limb segments - the length of the lower leg.

The results of determining the range of motion in the 
Table 1. Anthropometric indicators of single combats athletes

\begin{tabular}{|c|c|c|c|c|c|c|}
\hline \multirow[b]{2}{*}{ Indicator } & \multicolumn{3}{|c|}{ group $1(n=12)$} & \multicolumn{3}{|c|}{ group $2(n=17)$} \\
\hline & $\begin{array}{l}1 \\
\text { quartile }\end{array}$ & Midpoint & 3 quartile & $\begin{array}{l}1 \\
\text { quartile }\end{array}$ & Midpoint & $\begin{array}{l}3 \\
\text { quartile }\end{array}$ \\
\hline Body length, cm & 173.25 & 175.5 & 180.0 & 170.00 & 178.00 & 185.0 \\
\hline Body weight, kg & 66.50 & 75.0 & 90.0 & 63.00 & $68.00^{*}$ & 74.00 \\
\hline Chest circumference, $\mathrm{cm}$ & 88.25 & 96.00 & 101.0 & 86.00 & $89.00^{*}$ & 95.00 \\
\hline Chest circumference on inhalation, $\mathrm{cm}$ & 91.75 & 99.75 & 106.25 & 92.00 & $94.00^{*}$ & 99.00 \\
\hline Chest circumference on exhalation, $\mathrm{cm}$ & 81.75 & 92.00 & 96.50 & 84.00 & $87.00^{*}$ & 91.00 \\
\hline Hand dynamometry of the right hand, $\mathrm{kg}$ & 38.00 & 46.00 & 61.00 & 32.00 & $39.00^{*}$ & 44.00 \\
\hline Hand dynamometry of the left hand, kg & 35.00 & 49.00 & 53.00 & 30.00 & $40.00^{*}$ & 40.00 \\
\hline $\begin{array}{l}\text { Maximum grip frequency in pulse mode } \\
\text { with the right hand, abs. }\end{array}$ & 24.75 & 28.50 & 33.25 & 18.50 & 25.00 & 33.25 \\
\hline $\begin{array}{l}\text { Maximum grip frequency in pulse mode } \\
\text { with the left hand, abs. }\end{array}$ & 22.00 & 28.50 & 32.50 & 16.75 & $20.50^{*}$ & 30.00 \\
\hline Shoulder width, cm & 39.00 & 42.25 & 45.75 & 38.00 & $41.00^{*}$ & 42.00 \\
\hline The length of right shoulder, $\mathrm{cm}$ & 33.75 & 35.50 & 36.00 & 32.00 & 34.00 & 35.00 \\
\hline The length of right forearm, cm & 26.75 & 27.00 & 28.12 & 25.00 & 25.00 & 28.00 \\
\hline The length of left shoulder, cm & 33.75 & 35.50 & 36.00 & 32.00 & 34.00 & 35.00 \\
\hline The length of left forearm, cm & 26.75 & 27.00 & 28.12 & 25.50 & 26.00 & 28.00 \\
\hline The length of right thigh, $\mathrm{cm}$ & 38.00 & 40.00 & 41.75 & 38.00 & 40.00 & 43.00 \\
\hline The length of right lower leg, $\mathrm{cm}$ & 34.75 & 36.00 & 37.50 & 35.00 & $37.00^{*}$ & 39.00 \\
\hline The length of left thigh, $\mathrm{cm}$ & 38.00 & 40.00 & 41.75 & 38.00 & 40.00 & 43.00 \\
\hline The length of left lower leg, cm & 34.75 & 36.00 & 37.50 & 35.00 & $37.00^{*}$ & 39.00 \\
\hline Circumference of the right shoulder, $\mathrm{cm}$ & 33.25 & 34.25 & 39.12 & 28.00 & $30.00^{*}$ & 33.00 \\
\hline Circumference of right forearm, $\mathrm{cm}$ & 29.25 & 31.00 & 33.00 & 25.00 & $27.50^{*}$ & 28.00 \\
\hline Circumference of the left shoulder, $\mathrm{cm}$ & 32.25 & 33.75 & 39.37 & 27.50 & $30.50^{*}$ & 32.00 \\
\hline Circumference of left forearm, $\mathrm{cm}$ & 27.25 & 30.25 & 32.00 & 24.00 & $27.00^{*}$ & 28.00 \\
\hline Circumference of right thigh, $\mathrm{cm}$ & 54.75 & 59.00 & 60.75 & 52.00 & $54.50^{*}$ & 59.00 \\
\hline Circumference of right lower leg, $\mathrm{cm}$ & 36.75 & 39.00 & 40.75 & 35.00 & $37.00^{*}$ & 38.00 \\
\hline Circumference of left thigh, $\mathrm{cm}$ & 54.75 & 58.50 & 60.87 & 52.00 & $54.00^{*}$ & 59.00 \\
\hline Circumference of left lower leg, $\mathrm{cm}$ & 36.50 & 39.00 & 41.25 & 35.00 & $36.00^{*}$ & 37.00 \\
\hline
\end{tabular}

Note: $*$ - differences are significant $(p<0.05)$

Table 2. Goniometric indicators of single combats athletes

\begin{tabular}{|c|c|c|c|c|c|c|c|}
\hline \multirow[b]{2}{*}{ Joint, movement (degrees) } & & \multicolumn{3}{|c|}{1 group $(n=12)$} & \multicolumn{3}{|c|}{2 group (n=17) } \\
\hline & & $\begin{array}{l}1 \\
\text { quartile }\end{array}$ & Midpoint & $\begin{array}{l}3 \\
\text { quartile }\end{array}$ & $\begin{array}{l}1 \\
\text { quartile }\end{array}$ & Midpoint & $\begin{array}{l}\mathbf{3} \\
\text { quartile }\end{array}$ \\
\hline \multirow{4}{*}{ Right wrist joint } & flexion & 62.55 & 73.10 & 83.30 & 68.75 & 75.70 & 79.15 \\
\hline & extension & 52.80 & 58.30 & 64.05 & 52.10 & 63.60 & 70.85 \\
\hline & abduction & 37.75 & 45.20 & 54.00 & 31.80 & $36.60^{*}$ & 52.60 \\
\hline & adduction & 37.85 & 47.60 & 53.05 & 35.20 & $40.20^{*}$ & 44.15 \\
\hline \multirow{4}{*}{ Left wrist joint } & flexion & 67.15 & 72.70 & 77.60 & 64.25 & 69.20 & 87.25 \\
\hline & extension & 61.25 & 66.10 & 73.65 & 64.45 & $75.50^{*}$ & 85.30 \\
\hline & abduction & 50.00 & 51.40 & 57.80 & 33.55 & $43.50^{*}$ & 51.20 \\
\hline & adduction & 35.45 & 43.40 & 48.05 & 36.75 & 40.10 & 47.20 \\
\hline \multirow{2}{*}{ Right elbow joint } & flexion & 105.25 & 113.20 & 121.05 & 113.65 & $121.60^{*}$ & 131.85 \\
\hline & extension & 18.40 & 21.90 & 22.70 & 19.45 & 21.50 & 25.80 \\
\hline \multirow{2}{*}{ Left elbow joint } & flexion & 119.40 & 126.40 & 132.8 & 120.00 & 131.60 & 139.80 \\
\hline & extension & 21.90 & 25.50 & 25.95 & 24.40 & 26.40 & 30.65 \\
\hline \multirow{4}{*}{ Right shoulder joint } & flexion & 109.75 & 129.10 & 142.65 & 115.05 & 118.40 & 140.45 \\
\hline & extension & 34.15 & 51.90 & 58.00 & 40.55 & $63.00^{*}$ & 66.80 \\
\hline & abduction & 63.65 & 121.10 & 161.65 & 137.15 & $162.20^{*}$ & 179.45 \\
\hline & adduction & 22.10 & 38.00 & 108.95 & 27.95 & 33.70 & 62.45 \\
\hline \multirow{4}{*}{ Left shoulder joint } & flexion & 130.25 & 144.00 & 156.25 & 122.80 & 139.70 & 149.15 \\
\hline & extension & 39.30 & 53.60 & 58.40 & 34.45 & 56.90 & 66.25 \\
\hline & abduction & 128.80 & 144.20 & 172.6 & 143.20 & 157.70 & 165.75 \\
\hline & adduction & 27.75 & 31.00 & 61.20 & 25.10 & 30.70 & 43.10 \\
\hline
\end{tabular}

Note: ${ }^{*}$ - differences are significant $(p<0.05)$ 
joints of the hands are shown in Table 2.

The results of goniometric indicators also confirm the differences in the interquartile range of athletes in different types of martial arts. This indicator in wrestlers was higher for abduction and adduction in the right wrist joint, abduction in the left wrist joint. Percussion athletes were characterized by a greater interquartile range for extension of the left wrist joint, flexion of the right elbow joint, extension and abduction of the right shoulder joint. The magnitude of flexion of the right elbow joint was also greater according to Rosenbaum criterion $(\mathrm{Q}=9, \mathrm{p}<0.05)$.

\section{Discussion}

Physical development, somatotype and physical performance are the most significant factors of success in martial arts according to the available literature data. However, the features of development, which are predictors of success in specific types of martial arts, have not been definitively established. This led to the relevance of this study. The choice of indicators for the study was determined based on the specificity of sports. Conducting techniques and strikes by athletes necessitates the development of muscular strength of the limbs and an increase in the range of motion in the joints. Therefore, the most adequate research tool is anthropometric and goniometric indicators.

The correctness of this assumption is supported by the available data. Rossi [15] emphasizes the importance of controlling anthropometric parameters in martial arts. It is concluded that this is the most objective and effective criterion for assessing the preparation of athletes for competitions. Nichas et al. [16] note that anthropometric features are an important factor in karate success. The authors conducted an extensive kinanthropometric study of South African athletes. The positive relationship between the level of skill and the studied indicators was confirmed. Similar results were obtained by Gorski and Orysiak [17]. The authors found that the force of kicks of taekwondo athletes correlated with muscle mass and lean body mass. It is concluded that it is necessary to consider the anthropometric characteristics of athletes when assessing the level of skill.

The research design used by us (comparison of the characteristics of athletes of various types of martial arts) is widely used in sports science. A similar design option is used in the work of Apriantono et al. [18]. This analysis allows us to assess the specificity of the influence of the sport on the body of athletes. It also allows you to highlight the indicators and features that are most important for success.

The use of quartiles for data analysis is quite common in sports science. Small samples of athletes determine the nonparametric distribution of trait values. Determination of the quartile interval in this context allows one to adequately assess the differences. Korobeynikov et al. [19] confirmed the validity of this approach when analysing the functional state of kickboxers.

Shariat et al. [20] conducted a comparative analysis of the kinanthropometric characteristics of judo, karate and taekwondo athletes. It was found that judo athletes were characterized by a higher percentage of body fat, a greater amount of skin and fat folds and a lower amount of lean mass. It is concluded that it is necessary to consider the body composition of athletes in the selection and prediction of the growth of skill.

The established increase in body weight among wrestlers reflects the specificity of the sport. The effectiveness of the techniques depends on the technical and physical components of the training of athletes. The last component is largely due to body weight. In addition, training in wrestling is based on increasing muscle mass. It also makes body weight more important for success. The smaller value of body weight among representatives of percussion martial arts, in our opinion, illustrates the peculiarities of conducting a duel. The need to constantly move leads to additional energy costs. Less body weight reduces these costs. Jaksic et al. give similar results [21]. The authors studied the influence of martial arts training on the morphofunctional state of athletes. An increase in the main parameters of physical development (body weight, chest circumference), an improvement in strength indicators were confirmed.

Body weight is the most frequently used anthropometric indicator as a criterion for the effectiveness of training. Its dynamics allows predicting the growth of sportsmanship. In the work of Gaamouri et al. [22] control of body weight and somatotype components was used to assess the effectiveness of the use of dietary supplements. A similar approach was used by Martinelli et al. [23] to assess the status of taekwondo athletes in the pre-competition period and during post-competition recovery. Similar results are given by dos Santos et al. [24]. The use of the main anthropometric indicators (body length and weight, limb circumferences) and the characteristics of the somatotype made it possible to evaluate the effectiveness of the use of the enriched diet of Jiu-Jitsu athletes. Villarroel et al. [25] analyzed the state of Jiu-Jitsu athletes. The length and weight of the body, indicators of the level of fat are the most informative indicators in monitoring the functional state of athletes.

Bugaevsky et al. [26] note the importance of studying the somatotypes of athletes to improve the quality of training in single combats. The results of such a study of female sambo athletes are proposed to be used for the development and planning of training-competitive algorithms.

An increase in the interquartile range in wrestlers for all indicators of chest circumference indicates a greater adaptive potential. These data confirm the available results. Tumanian and Martirosov [27] made a similar conclusion when analyzing the features of the physique of Greco-Roman and freestyle wrestlers.

The specificity of the sport illustrates the increase in the intervals of hand strength indicators in static and impulse modes. Success in wrestling largely depends on a quick and high-quality grip. Such a grip allows the reception to be carried out successfully and effectively. These capabilities reflect wrist dynamometry and maximum grip 
frequency. The results obtained allow us to consider the high level of wrist dynamometry and the maximum grip frequency as factors of success in wrestling.

Tests based on frequency characteristics of movements are widely used in martial arts. Ojeda-Aravena et al. [28] studied the relationship between body composition characteristics and physical performance in taekwondo athletes. Determination of the frequency of strikes was used as a functional test. Correlation of the test results with the level of muscle mass was confirmed.

The increase in shoulder width in wrestlers reflects the increased development of the muscles of the shoulder girdle. It is also a factor in the success of most of the throws. The large size of the circumferences of the right and left shoulder and forearm in wrestlers illustrates a higher level of development of the muscles of the limbs. This is necessary for high-quality grip and receptions.

Representatives of percussion single combats were characterized by large values of the interquartile range of the shin lengths. In our opinion, this also reflects the specifics of the sport. In these martial arts, success is determined by effective striking. As you know, the most powerful blows are delivered by feet. An increase in the length of the lower leg changes the biomechanical features of the movements when such strikes are delivered, increases their effectiveness, and allows strikes to be made at a greater distance.

The increase in the range of motion in the elbow joints in athletes of percussion martial arts illustrates the trajectory of movement of the hands when striking. That is, this quality increases the likelihood of success in percussion martial arts.

A large range of motion in the wrist joint in wrestlers reflects better development of the hand. This increases the likelihood of a good and fast grip for effective reception. Thus, the analysis of goniometric parameters confirms the conclusions made in the analysis of morphological criteria. The range of motion of the wrist joint was higher in the wrestlers. This affects the grip quality. Among athletes of percussion single combats, goniometric indicators reflect the specifics of conducting a fight. Right elbow flexion, right shoulder extension and abduction are indicative of the effectiveness of hand striking. Increasing the amplitude of these movements allows you to hit harder. An interesting fact is that in athletes of percussion martial arts, an increase in the interquartile range for the indices of extension of the left wrist joint was found. In our opinion, this illustrates the features of defense, the ability to block enemy strikes. In this context, it is important that the difference is confirmed specifically for the left hand, which blocks the opponent's right hand punches.

\section{Conclusions}

The analysis of the morphological and goniometric indicators of athletes of various types of martial arts confirmed the specific effect of the sport on the body of athletes. The features that are the factors of success are highlighted. For wrestlers, these include hand strength in various modes. It allows you to grip quickly and efficiently. This is the basis for a successful wrestling technique. Adequate development of the muscles of the limbs is also important for the execution of throws in wrestling. The lengthening of the lower leg provides kicks in martial arts. The established goniometric features reflect the possibility of quality gripping, striking or blocking. The morphofunctional indicators used can be applied to predict the success of athletes in various types of martial arts.

\section{Conflict of interest}

The authors report no conflict of interest.

\section{References}

1. Matković BR, Mišigoj-Duraković M, Matković B. Morphological Differences of Elite Croatian Soccer Players Accordning to the Team Position. Coll. Antropol. 2003;27(1): 167-174.

2. Joksimović M, Skrypchenko I, Yarymbash K, Fulurija D, Nasrolahi S, Pantović M. Anthropometric characteristics of professional football players in relation to the playing position and their significance for success in the game. Pedagogics, Psychology, Medical-Biological Problems of Physical Training and Sports, 2019;23:224-30. https://doi.org/10.15561/18189172.2019.0503

3. Carter JEL, Ackland TR, Kerr DA, Stapff AB. Somatotype and size of elite female basketball players. Journal of Sport Sciences, 2005;23(10): 1057-1063. https://doi.org/10.1080/02640410400023233

4. Jagiello W, Jagiello M, Kalina RM, Barczynski BJ, Litwiniuk A, Klimczak J. Properties of body composition of female representatives of the Polish national fencing team - the sabre event. Biology of Sport. 2017;34(4):401-406. https://doi.org/10.5114/biolsport.2017.70526

5. Rejman M, Tyc L, Kociuba M, Bornikowska A, Rudnik D, Koziel S. Anthropometric predispositions for swimming from the perspective of biomechanics. Acta of Bioengineering and Biomechanics. 2018;20(4):151-159. https://doi.org/10.5277/abb-01254-2018-03

6. Dopsaj M, Markovic M, Kasum G, Jovanovic S, Koropanovski N, Vukovic M, et al. Discrimination of Different Body Structure Indexes of Elite Athletes in Combat Sports Measured by Multi Frequency Bioimpedance Method. International Journal of Morphology, 2017;35:199-207. https://doi.org/10.4067/S0717-95022017000100033

7. Burdukiewicz A, Pietraszewska J, Stachoń A, Andrzejewska J. Anthropometric profile of combat athletes via multivariate analysis. J Sports Med Phys Fitness, 2018;1657-1665. https://doi.org/10.23736/S0022-4707.17.07999-3

8. Konstantinova LI, Semenova EI, Okhlopkova ED, Efremova AV, Olesova LD, Krivoshapkina ZN, et al. Morphofunctional indicators of organism of the athleteswrestlers of Yakutia. Yakut Medical Journal, 2019:24-7. https://doi.org/10.25789/YMJ.2019.65.07

9. Jagiello W, Dornowski M, Jagiello M. Perkal's natural indicators method in assessing body composition properties in persons practising combat sports - an analysis research results. Archives of Budo Science of Martial Arts and Extreme Sports, 2018;14:75-80. 
10.Ishihara T, Kuroda Y, Mizuno M. Competitive achievement may be predicted by executive functions in junior tennis players: An 18-month follow-up study. Journal of Sports Sciences, 2019; 37(7): 755-761. https://doi.org/10.1080/02640414.2018.1524738

11. Mata-Ordonez F., Sanchez-Oliver A., Dominguez-Herrera R. Importance of Nutrition in Weight Loss Strategies in Combat Sports. Journal of Sport and Health Research, 2018;10(1): $1-12$.

12.Korobeynikov G. Link between neurodynamics and cognitive functions among athletes practicing different martial arts. Revista Iberoamericana de Psicologia del Ejercicio y el Deporte, 2021;16(1), 149-1544.

13.Casals C, Huertas JR, Franchini E, SterkowiczPrzybycień K, Sterkowicz S, Gutiérrez-García C, et al. Special Judo Fitness Test Level and Anthropometric Profile of Elite Spanish Judo Athletes. Journal of Strength and Conditioning Research, 2017;31:1229-35. https://doi.org/10.1519/JSC.0000000000001261

14.Marfell-Jones M, Olds T, Stewart A, Lindsay Carter LE. ISAK manual, International standards for Anthropometric Assessment. In International Society for the Advancement of Kinanthropometry; Published by The international society for the advancement of kinanthropometry, The University of South Australia Holbrooks Rd, Underdale, SA, Australia; 2012.

15.Rossi L. Evaluation of the body composition of female athletes of the Sao Paulo olympic project of the Paulista Karate Federation. RBNE-Revista Brasileira de Nutricao Esportiva. 2019;13(79):373-377.

16.Nichas A, Shaw BS, Millard L, Breukelman GJ, Shaw I. Kinanthropometric attributes of elite South African male kata and kumite karateka. Archives of Budo. 2020;16:181-194.

17.Gorski M, Orysiak J. Differences between anthropometric indicators and the impact force of taekwondo kicks performed with the dominant and non-dominant limb. Biomedical Human Kinetics, 2019;11(1):193-197. https://doi.org/10.2478/bhk-2019-0027

18.Apriantono T, Herman I, Winata B, Hasan MF, Juniarsyah AD, Ihsani SI, et al. Differences of physiological characteristics of taekwondo junior players vs pencak silat junior players. Physical Activity Review,2020;8(2): 9-15. https://doi.org/10.16926/par.2020.08.16

19.Korobeynikov G, Stavinskiy Y, Korobeynikova L. Connection between sensory and motor components of the professional kickboxers' functional state. Journal of Physical Education and Sport, 2020;20(5): 2701-2708. https://doi.org/10.7752/jpes.2020.05368

20.Shariat A, Shaw BS, Kargarfard M, Shaw I, Lam ETC. Kinanthropometric attributes of elite male judo, karate and taekwondo athletes. Rev Bras Med Esporte, 2017;23:260-3. https://doi.org/10.1590/1517-869220172304175654

21.Jaksic D, Mandic S, Maksimovic N, Milosevic Z, Roklicer R, Vukovic J, et al. Effects of a Nine-Month Physical Activity Intervention on Morphological Characteristics and Motor and Cognitive Skills of Preschool Children. International Journal of Environmental Research and Public Health, 2020;17:6609. https://doi.org/10.3390/ijerph17186609

22.Gaamouri N, Zouhal H, Hammami M. Effects of polyphenol (carob) supplementation on body composition and aerobic capacity in taekwondo athletes. Physiology \& Behavior. 2019; I 205(SI): 22-28. https://doi.org/10.1016/j.physbeh.2019.03.003

23. Martinelli HS, Castro Pereira Paixao MP. Nutritional profile of taekwondo athletes in period after and after competition under nutritional intervention. RBNE-Revista Brasileira de Nutricao Esportiva, 2019;13(78):195-205.

24.dos Santos PR, Gomes Rodrigues G da Costa, Ziegler Sanches F La Flor. Correlation between the use of supplements and body composition of jiu-jitsu athletes from Campo GrandeMS. RBNE-Revista Brasileira de Nutricao Esportiva. 2018;12(71): 344-352.

25.Villarroel JA, Rossini MC, Armenio VM e.a. Anthropometric and dietetic evaluation in jiu-jitsu practitioners in an academy of Sao Bernardo do Campo-SP. RBNE-Revista Brasileira de Nutricao Esportiva. 2018;12(70):135-142.

26.Bugaevsky K, Rybalko L, Zukow W. Research of Peculiarities of Formation of Inversive Sexual Somatotypes in Different Age Groups in Women Sambo. International Journal of Applied Exercise Physiology, 2019;8(4):120-126. https://doi.org/10.26655/IJAEP.2019.12.6

27.Tumanian GS, Martirosov EG. Constitution and sport. Moscow: Physical Culture and Sport; 1976. (in Russian)

28.Ojeda-Aravena A, Azocar-Gallardo J, Galle F, GarcíaGarcía JM. Relationship between the characteristics of body composition and general and specific physical performance in Chilean national taekwondo competitors of both sexes: an observational study. Revista Espanola de Nutricion Humana y Dietetica, 2020;24(2): 154-164. https://doi.org/10.14306/renhyd.24.2.969 
Information about the authors:

Olha O. Podrihalo; http://orcid.org/0000-0003-1519-5632; rovnayaolga77@ukr.net; Kharkiv State Academy of Physical Culture; Klochkovskaya str. 99, Kharkiv, 61022, Ukraine.

Leonid V. Podrigalo; (Corresponding author); http://orcid.org/0000-0002-7893-524X; leonid.podrigalo@gmail.com; Kharkiv State Academy of Physical Culture; Klochkovskaya str. 99, Kharkiv, 61022, Ukraine.

Wladyslaw Jagiello; http://orcid.org/0000-0001-7417-4749; wjagiello1@wp.pl; Department Combat Sports and Personal Training, Gdansk University of Physical Education and Sport; Gdańsk, Poland.

Olexandr V. Podavalenko; http://orcid.org/0000-0001-9143-3351; alekontp@ukr.net; Kharkiv State Academy of Physical Culture; Klochkovskaya str. 99, Kharkiv, 61022, Ukraine.

Irina P. Masliak; http://orcid.org/0000-0003-1306-0849; irochka.maslyak@gmail.com; Kharkiv State Academy of Physical Culture; Klochkovskaya str. 99, Kharkiv, 61022, Ukraine.

Yuri M. Tropin; https://orcid.org/0000-0002-6691-2470; tropin.yuri@gmail.com; Kharkiv State Academy of Physical Culture; Klochkovskaya str. 99, Kharkiv, 61022, Ukraine.

Margarita A. Mameshina; https://orcid.org/0000-0001-7397-3805; mameshina.rita@gmail.com; Kharkiv State Academy of Physical Culture; Klochkovskaya str. 99, Kharkiv, 61022, Ukraine.

Volodymyr O. Galimskyi; http://orcid.org/0000-0002-6953-5244; volodymyrgalimskyi@gmail.com; Flight Academy National Aviation University; Dobrovolskogo str. 1, Kropivnitsky, 25005, Ukraine.

Inna I. Galimska; http://orcid.org/0000-0003-0877-3991; volodymyrgalimskyi@gmail.com; Flight Academy National Aviation University; Dobrovolskogo str. 1, Kropivnitsky, 25005, Ukraine.

\section{Cite this article as:}

Podrihalo OO, Podrigalo LV, Jagiello W, Podavalenko OV, Masliak IP, Tropin YuM, Mameshina MA, Galimskyi VO, Galimska II. Morphofunctional characteristics of single combats athletes as factors of success. Physical Education of Students, 2021;25(5):265-271. https://doi.org/10.15561/20755279.2021.0502

This is an Open Access article distributed under the terms of the Creative Commons Attribution License, which permits unrestricted use, distribution, and reproduction in any medium, provided the original work is properly cited http://creativecommons.org/licenses/by/4.0/deed.en

Received: 25.08.2021

Accepted: 10.10.2021; Published: 30.10.2021 